\title{
Software SOLEEC Applied for Parabolic Trough Solar Collector Designing
}

\author{
Ernesto Enciso-Contreras, Juan Gabriel Barbosa-Saldaña, José Alfredo Jiménez-Bernal and Claudia del Carmen \\ Gutiérrez-Torres \\ SEPI-ESIME Zacatenco-LABINTHAP, Instituto Politécnico Nacional, Mexico City 07738, México
}

Received: April 30, 2014 / Accepted: May 23, 2014 / Published: July 25, 2014.

\begin{abstract}
The present work describes software SOLEEC (copyright 03-2012-070510302900-01 México), a numerical tool for PTC (parabolic trough collector) designing. Software SOLEEC is divided into two main parts. The first one allows solar resource assessment for a specific place on the Earth. The computation and assessment can be done for a specific day on the year, for one specific month and the monthly averages along the year. The last one gives annual charts such as: solar constant, Earth declination, insolation hours, and sunrise and sunset hours. The second part has four different execution options for PTC designing, that is, using options one and two user can get five different designs based on receiver outer diameter evaluating solar radiation data along the full year or only one solar radiation value (monthly), on the other hand options three and four were developed to compute the thermal evaluation for an operating collector for twelve solar radiation values (annually) or a specific month computation, respectively.
\end{abstract}

Key words: Software, PTC, solar radiation.

\section{Introduction}

Recently, energy production in the world is majorly generated by using fossil fuels, which residual gases are harmful, contributing to green house effect and as a consequence producing a nature disequilibrium inducing climate change and natural disasters happening often and often with more intensity. Together to the negative impact in the environment, is very important to consider that fossil combustibles are limited and no renewable, which causes a constant increase in market prices. Hence, it is clear that renewable energy must have a main participation to satisfy society's energy demand, not only in the present but also in future time.

Among renewable energies, solar energy has the highest potential, since the energy quantity that reaches on Earth is enough for satisfying the entire world demand [1]. Furthermore, solar energy can be

Corresponding author: Juan Gabriel Barbosa Saldaña, Ph.D., research fields: solar energy conversion, concentrating collectors, and numerical analysis. E-mail: jbarbosas@ipn.mx. converted directly into electricity (photovoltaic) or thermal energy (photothermal). About thermal energy, using PTCs (parabolic trough collectors) is possible to reach temperatures around $400{ }^{\circ} \mathrm{C}$, and recently this technology has became the most mature technology and profitable for before mentioned temperature levels [2].

On the other hand, the use of software for simulating solar processes has got a great important development in recent years. Using computational tools, users can get reliable information replacing the experimental process offering to the designer the possibility of combine different performance parameters for different conditions giving the opportunity to assess external effects that affects the configuration and finally obtain the best combination an optimum design.

For PTCs' analysis, some computational tools have been developed such as Dymola/Modelica software [3] using for analyzing a solar collector field for direct steam generation, where water enters to the field and 
is partially evaporated, after that is transported toward a steam separator. The condensed mass is then recirculated to the field's inlet while saturated steam is carried out to overheated section which basically is a similar solar field.

Other research for optimizing solar system with a numerical tool is the PTCDES [4], used for computing the steam flow produced in a solar system composed of a separator tank coupled to a PTC. In this software, the values for horizontal surface beam solar radiation are those of the monthly representative day and ambient air temperature for Nicosia, Cyprus. The system's heat losses are computed using the enthalpy difference between the hot water at the collector's exit and the stored water in the tank.

IPSE-pro [5] is a software, which main objective is the numerical simulation for a conventional combined cycle power plant, however in the last edition it has been modified for a solar plant assessment.

In order to contribute to engineering software for PTC designing, software SOLEEC [6] is presented in this work, which is an interactive tool for PTC designing and assessment as well as a solar resource evaluation. The software and its applicability are shown in the following sections.

\section{Methodology}

Software SOLEEC and its user interface were developed using MATLAB R2009a. After software execution, results are presented in charts, plots and tables for a simple interpretation. A thermodynamic balance on the receiver tube and solar resource assessment are the main points backing software SOLEEC. Fig. 1 shows a diagram with main PTCs geometric features.

Tracking systems are often used for PTC, the most used are: (1) orientation north-south tracking east-west, (2) earth axis parallel orientation, tracking east-west, (3) orientation east-west tracking north-south,

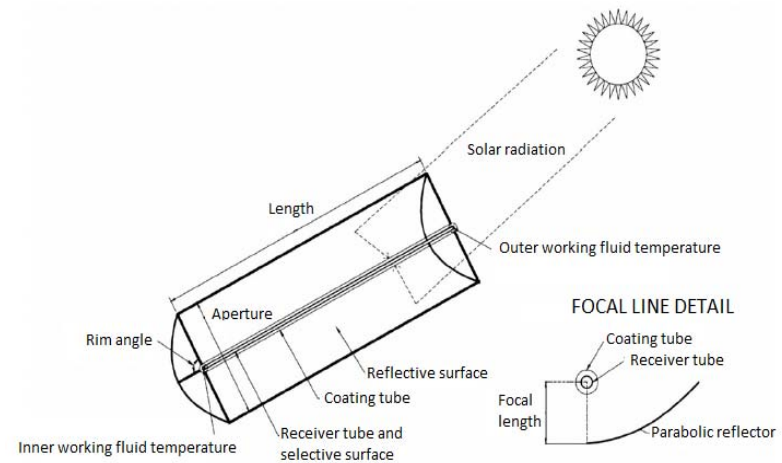

Fig. 1 Main PTC geometrical features.

and (4) two axis tracking system, it means, full tracking system. The last one is the less used for PTC due to the large length in the axial direction and manufacturing implications [7].

Software SOLEEC allows to select what kind of tracking system is going to be analyzed, once tracking system is chosen, a table shows the results, these are: solar radiation, incidence angle $(\theta)$ and slope collector angle $(\beta)$ for every hour in a specific day of the year.

Software SOLEEC has three options for solar resource assessment: (1) solar radiation for a specific day of the year, (2) solar radiation for a specified month and (3) averaged solar radiation for each month along the year. Some data such as latitude, longitude and altitude over the sea level of the place are needed as input data for the numerical computation. Hottel's model is used to compute solar radiation on Earth's surface assuming a $25 \mathrm{~km}$ visibility clear atmosphere and $2.5 \mathrm{~km}$ maximum altitude over the sea level [8].

PTC designing is based on the outer receiver diameter, for that reason, five different configurations using nominal diameters of $3 / 4,1,2,3$ and 4 are considered. Materials such as parabolic reflective surface, coating tube, receiver tube and selective surface can be chosen by the user for doing the computation.

Evaluating the thermal performance of a PTC in operation is other versatility of the software SOLEEC. In this case, the user must provide the solar collector's geometry, optical properties and construction's 
materials and some geometrical parameters. After obtaining the results, the user can analyze them in order to assess its efficiency, but if needed the SOLEEC options can be used for optimizing collector's operation. Fig. 2 shows the main menu of the software SOLEEC.

The heat gain is the most important parameter about thermal performance, this parameter is directly involved by all other parameters affecting PTC designing, and therefore, software SOLEEC internally develops an iterative process until Eqs. (1) and (2) are evenly closer.

$$
\begin{gathered}
Q_{u 1}=\dot{m} C_{p}\left(T_{f e}-T_{f i}\right) \\
Q_{u 2}=F_{R} A_{A}\left[S-\frac{A_{r}}{A_{a}} U_{L}\left(T_{f i}-T_{a}\right)\right]
\end{gathered}
$$

Eq. (1) represents the heat gained internally in the working fluid as a function of its thermal characteristics, while Eq. (2) represents the heat gain quantity on solar collector taking into account the solar radiation available, the heat losses and the collector's geometry, thus, both equations involve the same concept of energy gain, the first one as the working fluid and the second one as the collector's performance point of view [9].

Software SOLEEC was thought as a numerical tool for PTC designing. Although its enormous versatility some limitations must be observed before software execution as listed below: (1) the parabola rim angle is $90^{\circ}$ for all the configurations suggested, (2) there is no working fluid phase change, it means, $90{ }^{\circ} \mathrm{C}$ as a maximum temperature for water and $400{ }^{\circ} \mathrm{C}$ for syntetic oil, (3) only one coating tube is considered and (4) space between receiver and coating tube must be evacuated.

\section{Software SOLEEC Validation}

The Software SOLEEC's validation was realized using values from experimental data reported by Sandia National Laboratories, USA and numerical analysis data carried out in the Centro de Investigación en Energía UNAM, México [10]. Table

\section{SOLEEC}

Software for parabolic trough solar collector desgning and assessment as well as solar resource evaluation Solar resource

\begin{tabular}{|c|}
\hline Specific day data \\
\hline Monthly average data \\
\hline Monthly average data along the year \\
\hline
\end{tabular}

Parabolic trough solar collector PTC designing for 12 values PTC designing for 1 value PTC assessment for 12 values PTC assessment for 1 value

Exit

Fig. 2 Software SOLEEC main menu.

1 shows comparison between data obtained in the studies before mentioned and data obtained using software SOLEEC. For validation process, same PTC characteristics were used for all the proofs. Test 1 was realized using water as working fluid while synthetic oil Syltherm 800 was used for the rest of the proofs. Table 1 shows the error obtained when experimental data are compared with software SOLEEC results. A $6.70 \%$ maximum error on the heat gain in the fifth test and $1.44 \%$ as minimal error on last test when comparing SOLEEC results versus experimental data, while a $4.93 \%$ as maximum error when comparing with the numerical data. Hence software SOLEEC reliability for PTCs designing and assessment has a great exactitude and good accuracy, therefore its use as numerical tool has been proven.

Once software has been described and its reliability proven, functionality for different application examples are shown in the next section, in this case the location place for the analysis is in the Southern hemisphere.

\section{Results and Application}

Software SOLEEC application for PTC designing and solar facility assessment is used to evaluate a locality in Buenos Aires, Argentina, and the main 
Table 1 Validation software SOLEEC results.

\begin{tabular}{|c|c|c|c|c|c|c|}
\hline Tests & 1 & 2 & 3 & 4 & 5 & 6 \\
\hline \multicolumn{7}{|c|}{ Volumetric flow (l/min) } \\
\hline Exp. & 18.4 & 47.7 & 47.8 & 49.1 & 54.7 & 55.5 \\
\hline Num. & 18.4 & 47.7 & 47.8 & 49.1 & 54.7 & 55.5 \\
\hline SOLEEC & 18 & 45.66 & 46.52 & 48.28 & 53.27 & 54.70 \\
\hline Error (\%)* & 2.17 & 4.28 & 2.68 & 1.67 & 2.61 & 1.44 \\
\hline Error $(\%)^{* *}$ & 2.17 & 4.28 & 2.68 & 1.67 & 2.61 & 1.44 \\
\hline \multicolumn{7}{|l|}{ Heat gain $(\mathrm{W})$} \\
\hline Exp. & $22,884.3$ & $26,404.0$ & $26,771.7$ & $26,881.9$ & $24,918.0$ & $24,865.8$ \\
\hline Num. & $22,808.7$ & $25,741.3$ & $26,480.9$ & $26,556.3$ & $24,212.2$ & $24,653.6$ \\
\hline SOLEEC & $22,243.6$ & $24,889.3$ & $25,510.3$ & $25,563.2$ & $23,247.5$ & $23,531.9$ \\
\hline Error (\%)* & 2.80 & 5.74 & 4.71 & 4.91 & 6.70 & 5.36 \\
\hline Error $(\%)^{* *}$ & 2.47 & 3.31 & 3.66 & 3.74 & 3.98 & 4.55 \\
\hline \multicolumn{7}{|c|}{ Thermal efficiency (\%) } \\
\hline Exp. & $72.63 \pm 1.91$ & $72.51 \pm 1.95$ & $70.90 \pm 1.92$ & $70.17 \pm 1.81$ & $70.25 \pm 1.90$ & $67.98 \pm 1.86$ \\
\hline Num. & 72.39 & 70.69 & 70.13 & 69.32 & 68.26 & 67.40 \\
\hline SOLEEC & 70.60 & 68.35 & 67.56 & 66.73 & 65.54 & 64.33 \\
\hline Error (\%)* & 2.79 & 5.74 & 4.71 & 4.90 & 6.70 & 5.37 \\
\hline Error (\%)** & 2.47 & 3.31 & 3.66 & 3.74 & 3.98 & 4.55 \\
\hline
\end{tabular}

Exp.: Experimental, Num.: Numerical.

*Error comparing software SOLEEC results against experimental data.

**Error comparing software SOLEEC results against numerical analysis data.

designing condition is the water temperature that must be equal to $90{ }^{\circ} \mathrm{C}$ all over the year. Buenos Aires is located at $34.52^{\circ}$ south latitude and $58.49^{\circ}$ west longitude, $25 \mathrm{~m}$ altitude over the sea level. Solar radiation on the horizontal plane is going to be determined using the Hottel's model, using the third icon on the SOLEEC interface (Fig. 2) and introducing the data just before mentioned. Results are presented in Fig. 3, which shows solar radiation values along the year and some charts allowing the solar resource estimate.

Fig. 3 shows some charts as: solar constant, Earth's declination, sunrise and sunset time and insolation hours. This last chart is important because shows that several insolation hours are available for this location, having 14 hours on the longest day and more than 9 for the worst day, in this interval the solar energy is available along the year. Sunrise and sunset time's chart can be useful if a tracking system is going to be considered as part of the solar system allowing it to shut on or shut off. The bottom left chart on the interface shows the extraterrestrial solar radiation and the solar radiation on Earth surface in a bar diagram for every month along the year, same data are shown on the top table and they will be used for PTC thermal design. The extraterrestrial and solar irradiations on the place are summarized in Table 2. The second column in this table is computed based on the Hottel's model for clear visibility. These values can be used for computing the PTC design. However, SOLEEC allows the user to introduce the Earth measured data or registered radiation data for the location in question.

It is very important to mention that the software SOLEEC allows three different options for reflective surface (anodized aluminum, silver covering and aluminized acrilic) and three options for selective surface (black chrome, plumbum sulfate painting and copper oxide). For the receiver tube the options are stainless steel and copper, while for the coating they are borosilicate and acrilic. Finally, there are three 


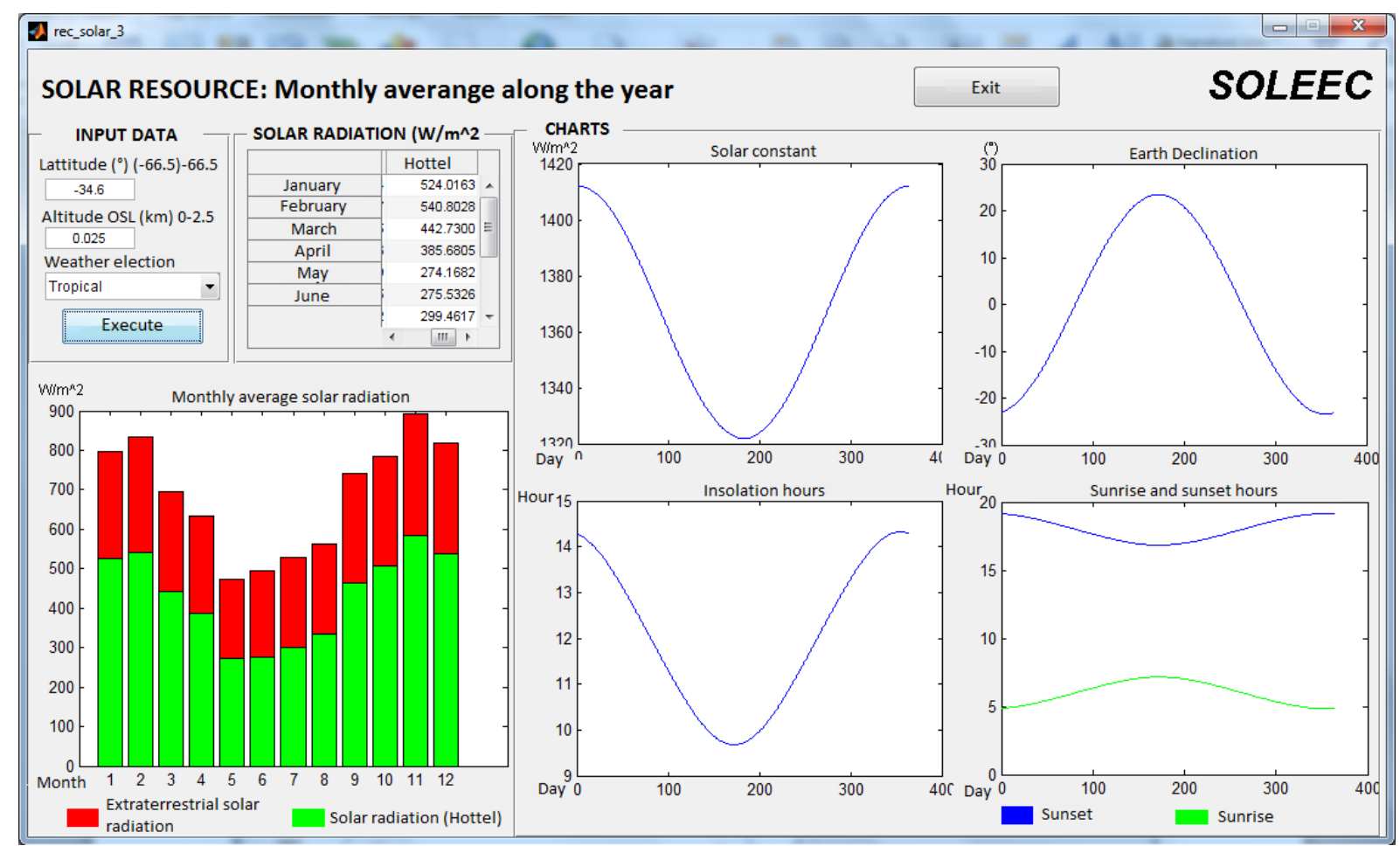

Fig. 3 Solar radiation data along the year for Buenos Aires, Argentina.

Table 2 Solar radiation along the year in Buenos Aires, Argentina.

\begin{tabular}{lll}
\hline Month & $\begin{array}{l}\text { Extraterrestrial } \\
\text { radiation }\left(\mathrm{W} / \mathrm{m}^{2}\right)\end{array}$ & $\begin{array}{l}\text { solar } \\
\text { Solar radiation } \\
\text { on Earth surface } \\
(\text { Hottel })\left(\mathrm{W} / \mathrm{m}^{2}\right)\end{array}$ \\
\hline Jan. & 797.53 & 524.02 \\
Feb. & 833.30 & 540.80 \\
Mar. & 695.90 & 442.73 \\
Apr. & 634.60 & 385.68 \\
May & 474.57 & 274.17 \\
Jun. & 493.92 & 275.53 \\
Jul. & 527.31 & 299.46 \\
Aug. & 561.61 & 334.52 \\
Sept. & 739.79 & 464.05 \\
Oct. & 783.93 & 505.78 \\
Nov. & 893.45 & 585.52 \\
Dec. & 816.96 & 537.12 \\
\hline
\end{tabular}

different options for working fluid; water, Therminol VP1 and Siltherm 800.

Table 3 shows the collector's construction materials used for the application example while Table 4 shows local ambient conditions for being assessed by software SOLEEC. It can be inferred that the software SOLEEC allows the computation for different collector materials, but in the application example
Table 3 Collector used materials.

\begin{tabular}{ll}
\hline Reflective surface & Anodized aluminum \\
\hline Selective surface & Black chrome \\
Receiver tube & Copper \\
Coating tube & Borosilicate \\
Working fluid & Water \\
\hline
\end{tabular}

Table 4 Ambient conditions of Buenos Aires City, Argentina.

\begin{tabular}{ll}
\hline Air velocity $(\mathrm{m} / \mathrm{s})$ & 3 \\
\hline Ambient temperature $\left({ }^{\circ} \mathrm{C}\right)$ & 17.6 \\
Inner collector working fluid temperature $\left({ }^{\circ} \mathrm{C}\right)$ & 15 \\
Outer collector working fluid temperature $\left({ }^{\circ} \mathrm{C}\right)$ & 90 \\
Solar radiation incidence angle $\left({ }^{\circ}\right)$ & 10 \\
\hline
\end{tabular}

discussed in this work, the materials considered for the computation are those listed in Table 4. In a similar way, the software offers the options of selecting different operating ambient conditions. Here for the application example, the conditions are those summarized in Table 4. Any change in Tables 3 or 4 will result in a different designing, this feature is the most relevant in the numerical tool developed which is synonymous of versatility.

Fig. 4 shows software SOLEEC interface results 


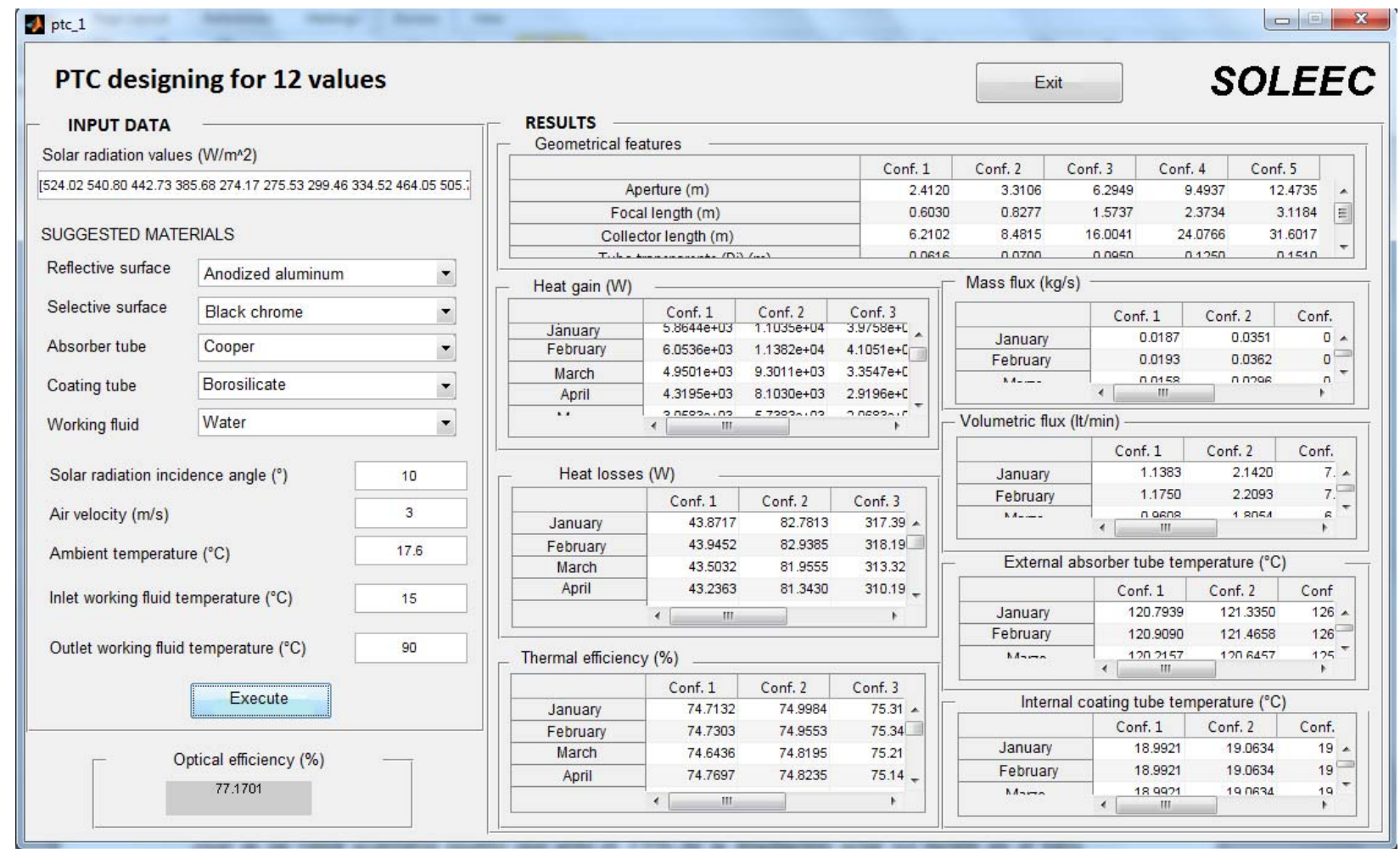

Fig. 4 Interface showing thermal characteristics for software SOLEEC suggested configurations.

considering an evaluation all along the year. The results are presented for five different configurations. On the left hand side of the figure, it can be observed the user data given as input for solar irradiance (values from solar radiation on Earth surface showed in Table 2), and materials for solar collector construction as presented in Table 3.

At the bottom on left hand side of Fig. 4, it can be observed that the optical efficiency of the PTC is $77.17 \%$, which can be intepreted that a good combination of materials for this collector was done, hence energy gain is acceptable due to only $22.83 \%$ of energy available is not reaching the receiver.

On the right hand side of Fig. 4, results ordered in table are shown for suggested five configurations, as can be seen, software offers tables for geometrical features, heat gain, heat losses, mass flow, volumetric flow, external receiver tube temperature, internal coating tube temperature and thermal efficiency, and for all months in the year, in this way, results can be compared for every designing configuration and make the best choice according to the dimensions and thermal efficiency. In order to have a better understanding of the software applicability, the PTC features given after the SOLEEC execution are presented in Tables 5-9.

Table 5 shows geometrical features for every configuration given by software SOLEEC. Here, it can be observed that every configuration is a function of outer receiver tube nominal diameter, resulting in collector lengths from $6.21 \mathrm{~m}$ to $31.6 \mathrm{~m}$, and apertures from $2.4 \mathrm{~m}$ to $12.47 \mathrm{~m}$. In similar way, the focal length varies from $0.60 \mathrm{~m}$ to $3.11 \mathrm{~m}$. These geometrical measures were computed considering that for all the configurations the solar energy will be completely reaching the receiver tube transmitting this energy to the working fluid.

The volumetric flow is an important feature directly involved with the heat gain given by PTC and by its dimensions. The result of the volumetric flow computations for the five different configurations along the year are summarized in Table 6. The values 
Table 5 PTC geometrical characteristics.

\begin{tabular}{llllll}
\hline \multicolumn{7}{c}{ Configurations } & & & \\
\hline & 1 & 2 & 3 & 4 & 5 \\
\hline Receiver tube & $3 / 4$ & 1 & 2 & 3 & 4 \\
diameter (in) & 2.41 & 3.31 & 6.29 & 9.49 & 12.47 \\
Aperture (m) & 0.60 & 0.82 & 1.57 & 2.37 & 3.11 \\
Focal length (m) & 6.21 & 8.48 & 16.00 & 24.07 & 31.6 \\
Collector length (m) & 0.06 & 0.07 & 0.09 & 0.12 & 0.15 \\
Internal coating & 4 & 5 & 5 & 5 & 7 \\
tube diameter (m) & 4 & & & \\
\hline
\end{tabular}

Table 6 Volumetric flow (lt/min) necessary for covering stablished temperature.

\begin{tabular}{llllll}
\hline \multirow{2}{*}{ Month } & \multicolumn{2}{l}{ Configurations } & & & \\
\cline { 2 - 5 } & 1 & 2 & 3 & 4 & 5 \\
\hline Jan. & 1.13 & 2.14 & 7.71 & 17.5 & 30.25 \\
Feb. & 1.17 & 2.20 & 7.96 & 18.1 & 31.23 \\
Mar. & 0.96 & 1.80 & 6.51 & 14.7 & 25.53 \\
Apr. & 0.83 & 1.57 & 5.66 & 12.8 & 22.21 \\
May & 0.59 & 1.11 & 4.01 & 9.11 & 15.72 \\
Jun. & 0.59 & 1.12 & 4.03 & 9.16 & 15.80 \\
Jul. & 0.64 & 1.21 & 4.38 & 9.96 & 17.20 \\
Aug. & 0.72 & 1.36 & 4.90 & 11.1 & 19.24 \\
Sept. & 1.004 & 1.89 & 6.83 & 15.5 & 26.76 \\
Oct. & 1.09 & 2.06 & 7.44 & 16.9 & 29.19 \\
Nov. & 1.27 & 2.39 & 8.62 & 19.6 & 33.83 \\
Dec. & 1.163 & 2.19 & 7.91 & 17.9 & 31.02 \\
\hline
\end{tabular}

in Table 6 represents the volumetric flow rate that must be imposed to the PTC for ensuring that in the PTC exit the temperature of the working fluid is the one required. The results show that in the summer volumetric flow is almost double than in the winter. Here the software's user must consider that for a higher volumetric flow the power of the pump will be increased.

Similarly in Table 7, the heat gain by the PTC is presented. It can be appreciated that for summer it will be $100 \%$ greater than for winter. The importance on Table 7 lays on the fact that for the studied case is not reliable using PTC for some seasons because the heat gain is relatively small, and then the efficiency conversion will be small. Another important fact is that if the PTC is small then the heat gain will be small as can be observed in Tables 5 and 7 and configurations 1 and 2. For configurations 4 and 5, the heat gain is extremely large, but the geometry needed is enormous resulting in a high manufacturing cost and in a higher inversion for installation.

Table 8 shows the heat losses. In general, it can be observed that these values are low, this behavior is an effect due to the outer receiver temperature because is directly involved with radiative heat losses which are the highest kind of losses in a PTC. Another reason why this parameter is kept low is because of the chosen collector construction materials, which in general have good thermal properties.

Table 9 shows the thermal efficiency which is directly related to gain and heat losses. A combination of high heat gain and low heat loss gives as a result that for all the configurations the thermal efficiency has high values. In general the thermal efficiency goes from $74.103 \%$ to $75.53 \%$, these values are obtained because of the low difference's temperature between the inlet and outlet working fluid, in this case the value is around $75{ }^{\circ} \mathrm{C}$. When synthetic oil is used, 
Table 7 Heat gain (W).

\begin{tabular}{|c|c|c|c|c|c|}
\hline \multirow{2}{*}{ Month } & \multicolumn{5}{|c|}{ Configurations } \\
\hline & 1 & 2 & 3 & 4 & 5 \\
\hline Jan. & $5,864.4$ & 11,035 & 39,758 & 90,363 & 155,880 \\
\hline Feb. & $6,053.6$ & 11,382 & 41,051 & 93,263 & 160,920 \\
\hline Mar. & $4,950.1$ & $9,301.1$ & 33,547 & 76,238 & 131,540 \\
\hline Apr. & $4,319.5$ & $8,103.0$ & 29,196 & 66,337 & 114,450 \\
\hline May & $3,058.3$ & $5,738.3$ & 20,683 & 46,978 & 81,030 \\
\hline Jun. & $3,058.3$ & $5,769.8$ & 20,809 & 47,231 & 81,440 \\
\hline Jul. & $3,342.1$ & $6,274.3$ & 22,606 & 51,361 & 88,628 \\
\hline Aug. & $3,720.4$ & $7,031.0$ & 25,286 & 57,446 & 99,128 \\
\hline Sept. & $5,170.8$ & $9,742.5$ & 35,187 & 79,926 & 137,910 \\
\hline Oct. & $5,643.7$ & 10,625 & 38,371 & 87,178 & 150,430 \\
\hline Nov. & $6,558.1$ & 12,328 & 44,456 & 101,020 & 174,320 \\
\hline Dec. & $5,990.5$ & 11,287 & 40,767 & 92,633 & 159,820 \\
\hline
\end{tabular}

Table 8 Heat losses to the ambient $(\mathrm{W})$.

\begin{tabular}{llllll}
\hline \multirow{2}{*}{ Month } & \multicolumn{5}{l}{ Configurations } \\
\cline { 2 - 6 } & 1 & 2 & 3 & 4 & 5 \\
\hline Jan. & 43.872 & 82.781 & 317.395 & 756.656 & $1,338.6$ \\
Feb. & 43.945 & 82.939 & 318.190 & 758.755 & $1,342.5$ \\
Mar. & 43.503 & 81.956 & 313.329 & 745.714 & $1,318.0$ \\
Apr. & 43.236 & 81.343 & 310.199 & 737.201 & $1,301.9$ \\
May & 42.677 & 80.023 & 303.203 & 717.838 & $1,265.0$ \\
Jun. & 42.677 & 80.041 & 303.317 & 718.119 & $1,265.5$ \\
Jul. & 42.805 & 80.335 & 304.901 & 722.600 & $1,274.2$ \\
Aug. & 42.974 & 80.763 & 307.146 & 728.819 & $1,286.0$ \\
Sept. & 43.594 & 82.172 & 314.445 & 748.696 & $1,323.6$ \\
Oct. & 43.785 & 82.592 & 316.524 & 754.297 & $1,334.2$ \\
Nov. & 44.137 & 83.355 & 320.210 & 764.152 & $1,352.6$ \\
Dec. & 43.921 & 82.896 & 318.017 & 758.302 & $1,341.7$ \\
\hline
\end{tabular}

Table 9 Collector thermal efficiency (\%).

\begin{tabular}{llllll}
\hline Month & \multicolumn{2}{l}{ Configurations } & \multicolumn{3}{l}{5} \\
\cline { 2 - 6 } & 1 & 2 & 3 & 4 & 75.46 \\
\hline Jan. & 74.71 & 74.99 & 75.31 & 75.44 & 75.49 \\
Feb. & 74.73 & 74.95 & 75.34 & 75.44 & 75.37 \\
Mar. & 74.64 & 74.82 & 75.21 & 75.33 & 75.28 \\
Apr. & 74.77 & 74.82 & 75.14 & 75.24 & 74.97 \\
May. & 74.47 & 74.53 & 74.88 & 74.96 & 74.98 \\
Jun. & 74.10 & 74.57 & 74.96 & 74.99 & 75.08 \\
Jul. & 74.50 & 74.61 & 74.93 & 75.03 & 75.175 \\
Aug. & 74.24 & 74.85 & 75.0 & 75.12 & 75.39 \\
Sept. & 74.38 & 74.77 & 75.2 & 75.35 & 75.45 \\
Oct. & 74.49 & 74.81 & 75.3 & 75.40 & 75.53 \\
Nov. & 74.77 & 74.98 & 75.36 & 75.48 & 75.48 \\
Dec. & 74.45 & 74.84 & 75.33 & 75.45 & \\
\hline
\end{tabular}


due to higher temperature differences, thermal efficiency is diminished notoriously; this effect can be consulted on reference [4].

PTC have great thermal and optical efficiencies as can be observed in tables before presented. Next user's task is determining the best configuration that covers its necessities. Taking volumetric flow as a designing parameter can be concluded that configurations 1 and 2 are adequate for hot water in houses, hotels, pools and hospitals, while configurations 3-5 could be used for industrial processes where higher volume of hot water is required.

Feasibility for PTC installations due to solar radiation available along the year in this location is proven; despite the heat gain in winter is so low, almost half in comparison to summer as mentioned previously, this is enough for satisfying the heating requirements.

This way, software SOLEEC versatility for PTCs designing and assessment as well as solar resource assessment as a function of location where solar system is pretended to be installed has been proved.

\section{Conclusions}

Software SOLEEC application developed in LABINTHAP, Instituto Politécnico Nacional in Mexico was presented, which main objective is PTC designing and assessment as well as solar resource assessment. It has some limitations such as: parabola's rim angle of $90^{\circ}$, no phase change in the working fluid, only one concentric coating tube is considered and space between receiver and coating tubes must be evacuated.

Software SOLEEC is effective for PTC designing. The user must enter geographic data for the location and then chooses among different construction materials suggested by the software and indicates the working fluid as well as the desired temperature leaving the collector. Using these data it can be obtained five different geometrical configurations, the heat gain and heat loss to ambient, volumetric fluid flow, temperatures about receiver and coating tubes and thermal efficiency.

Software SOLEEC presents the results on tables, first computes the solar radiation available in a specific location in the way of monthly averages along the year. Solar radiation computed varies from 274.17 $\mathrm{W} / \mathrm{m}^{2}$ to $585.52 \mathrm{~W} / \mathrm{m}^{2}$, therefore, the location studied has great quantity of energy available on summer for installing a solar system presenting a well performance. Even though in winter months the energy available is diminished, some energy necessities could be still satisfied.

Finally, five different PTC configurations as a function of the energy requirement are showed by software SOLEEC. As could be observed a good optical efficiency was reached $77.17 \%$, due to the well election of chosen construction materials. On the other hand, the greater the volumetric fluxes obtained the greater the heat gained, having since $6.5 \mathrm{~kW}$ for configurations 1 , to $17.4 \mathrm{~kW}$ in configuration 5 .

The results ordered in tables given after the software execution allows the user to optimize the PTC's geometric configuration that best satisfies its energy requirements.

\section{References}

[1] Johnson, G. 2009. “Connected with the sun”, National Geographic in Spanish 25: 3-10.

[2] Zarza, E. 2004. "Medium Temperature Solar Concentrators (Parabolic-Troughs Collectors)." Solar Energy Conversion and Photoenergy Systems 1: 1-9.

[3] Birnbaum, J., Feldhoff, J., Fitchner, M., Hirsch, T., Jöcker, M., Pitz-Paal, R., and Zimmermann, G. 2011. "Steam Temperature Stability in a Direct Steam Generation Solar Power Plant.” Solar Energy 85: 660-68.

[4] Kalogirou, S., Lloyd, S., and Ward, J. 1997. "Modelling, Optimisation and Performance Evaluation of a Parabolic Trough Solar Collector Steam Generation System.” Solar Energy 60: 49-59.

[5] Eck, M., and Zarza, E. 2006. "Saturated Steam Process with Direct Steam Generating Parabolic Troughs.” Solar Energy 80: 1424-33. 
[6] Enciso, E. 2012. "Software Implementation for Parabolic Trough Solar Collector Designing.” M.Sc. thesis, Instituto Politécnico Nacional.

[7] Kalogirou, S. 2001. Solar Engineering Processes and Systems. 1st edition. New York: Elsevier.

[8] Hottel, H. C. 1976. "A Simple Model for Estimating the Transmittance of Direct Solar Radiation through Clear Atmospheres.” Solar Energy 18 (2): 129-34.
[9] Duffie, A. J., and Beckman, A. W. 2006. Solar Engineering of Thermal Processes. 3rd edition. Wisconsin: John Wiley and Sons.

[10] García, V. O., and Velázquez, N. 2009. "Numerical Simulation of Parabolic Trough Solar Collector: Improvement Using Counter Flow Concentric Circular Heat Exchangers." International Journal of Heat and Mass Transfer 52: 597-609. 